\title{
Short and long term impacts of COVID-19 on the pharmaceutical sector
}

\author{
Nayyereh Ayati ${ }^{1}$ (D) Parisa Saiyarsarai ${ }^{1,2}$ (I) $\cdot$ Shekoufeh Nikfar ${ }^{1,2,3}$ (i)
}

Received: 12 May 2020 / Accepted: 23 June 2020 / Published online: 3 July 2020

(C) Springer Nature Switzerland AG 2020

\begin{abstract}
Background The novel coronavirus disease 2019 (COVID-19) was characterized as a global pandemic by the WHO on March 11th, 2020. This pandemic had major effects on the health market, the pharmaceutical sector, and was associated with considerable impacts; which may appear in short and long-term time-horizon and need identification and appropriate planning to reduce their socio-economic burden.

Objectives Current short communication study assessed pharmaceutical market crisis during the COVID-19 era; discussing short- and long-term impacts of the pandemic on the pharmaceutical sector.

Results Short-term impacts of COVID-19 pandemic includes demand changes, regulation revisions, research and development process changes and the shift towards tele-communication and tele-medicine. In addition, industry growth slow-down, approval delays, moving towards self-sufficiency in pharm-production supply chain and trend changes in consumption of health-market products along with ethical dilemma could be anticipated as long-term impacts of COVID-19 pandemic on pharmaceutical sector in both global and local levels.

Conclusion The pandemic of COVID-19 poses considerable crisis on the health markets, including the pharmaceutical sector; and identification of these effects, may guide policy-makers towards more evidence-informed planning to overcome accompanying challenges.
\end{abstract}

Keywords COVID-19 • Corona virus · Pharmaceutical industry · Pharmaceutical market · Health market · Tele-health . SARS-CoV-2

\section{Introduction}

In December 2019, the novel coronavirus disease (COVID-19) was discovered and identified in Wuhan, China. On March 11th,

Shekoufeh Nikfar

nikfar_sh@tums.ac.ir

1 Department of Pharmacoeconomics and Pharmaceutical Administration, School of Pharmacy, Tehran University of Medical Sciences, Tehran, Iran

2 Evidence-Based Evaluation of Cost-Effectiveness and Clinical Outcomes Group, Pharmaceutical Sciences Research Center (PSRC), and the Pharmaceutical Management and Economics Research Center (PMERC), The Institute of Pharmaceutical Sciences (TIPS), Tehran University of Medical Sciences, Tehran, Iran

3 Personalized Medicine Research Center, Endocrinology and Metabolism Clinical Sciences Institute, Tehran University of Medical Sciences, Tehran, Iran the COVID-19 outbreak was characterized as a global pandemic by the world health organization (WHO) [1]. In the following months, COVID-19 rapidly spread around the globe and infected about 2.5 million people by April 23, 2020 [1]. The COVID-19 pandemic affected world economics, including the pharmaceutical sector. While currently there is no definitive treatment for this novel infectious disease, pharmaceutical industry is assisting governments to address the COVID-19 unmet needs, from research and development actions on potential treatment strategies to balancing medicines supply chain in the time of crisis. Along this, pharmaceutical sectors are struggling to maintain natural market flow; as the recent pandemic affects access to essential medicines at an affordable price, which is the main goal of every pharmaceutical system [2].

Alongside of evaluation the pharmaceutical system challenges in global level, the situation analysis of this industry in developing country with pharmaerging market, because of diversities, could highlight more impacts. Assessment of Iran as a 
developing country that was extremely affected by COVID-19 disease could be a good example for demonstration.

To the best of our knowledge, this is the first to identify these challenges in the context of a developing country with a pharmerging market. Iran, as a developing middle-income country, has a generic-based pharmerging market [3]; which is regulated under local national drug policy (NDP), last updated on 2014. The main components of Iran's NDP are generic-based medicine policy, promotion of local production, price control and formulation-based national industry [4]. Iran ministry of health $(\mathrm{MOH})$ supported local production aiming to improve availability and affordability of medicines; which are resulted in improved access to the quality medicines in Iran [5]. Although more than $95 \%$ (in terms of sale volume) of marketed pharmaceuticals in Iran are produced locally [6], but the dependence of the production of these medicines on the import of raw materials is a challenging issue. Currently, more than half of the active pharmaceutical ingredient (API) are produced in the country, and the remaining are supplied by reputable companies in India and China, and in some cases by some European and eastern European companies [4]. The dependence of medicine production on the importation of raw materials from countries such as China, which are affected by COVID-19, is one of the serious concerns of pharmaceutical sector.

As of April 28, 2020, the number of people infected with the SARS-CoV-2 in Iran was 0.9 million [7] with death ratio of $1.38 \%$; which was consistent with the adjusted statistics of the world [8]. The overall cumulative COVID-19-associated hospitalization rate was from $<0.1 \%$ in $10-19$ year-olds to $4.3 \%$ in $40-49$ year-olds and doubled in $50-59$ year-olds to $8.2 \%$ based on worldwide data [8].

Current short-communication study assessed pharmaceutical market crisis during the COVID-19 era; discussing shortand long-term impacts of the pandemic on pharmaceutical market natural flow and regulations, first at the global and then at Iran's national level as a case in point for developing countries. Identification of these effects is essential for policymaker guidance towards more evidence-informed planning to overcome accompanying challenges.

\section{Results}

\section{COVID-19 short and long-term impacts on pharma- ceutical sector}

COVID-19 may be seen as a century's opportunity for pharmaceutical industry; as it increases the demand for prescription medicines, vaccines and medical devices. This can be seen as one of the main short-term effect of COVID-19 epidemic; however, there are more short and long-term implications to it; which will be discussed below:
Short-term impacts Demand change, supply shortages, panic buying and stocking, regulation changes and shift of communication and promotions to remote interactions through technology and research and development (R\&D) process changes can be seen as short-term impacts of COVID-19 on the health market.

1. Demand change, which leads to shortage, in the case of induced demand and panic-buying of oral homemedications especially for chronic disease may be due to the pandemic (COVID-19-related), and also shortages due to supply-chain inconsistencies.

- COVID-19-related: Increased hospitalization, incidence of COVID-19-related pneumonia and increased demand for assigning patients to ventilators, contributes to related prescription medicine shortages. A medicine shortage is defined as a "supply issue that affects how the pharmacy prepares or dispenses a drug product or influences patient care when prescribers must use an alternative agent" [9]. On the global levels, many regulatory authorities announced confirmed shortage list, mostly including potential COVID-19 treatments and also associated pneumonia. For example, United States food and drug administration (FDA) shortage list included anti-COVID-19 potential pharmacotherapies, hydroxychloroquine (HQC) and chloroquine (QC), and also frequently prescribed medications for COVID-19 hospitalized patients with respiratory signs in critical care units, azithromycin, dopamine, dobutamine, fentanyl, heparin, midazolam, propofol and dexmedetomidine [10]. In addition, the American Society of HealthSystem Pharmacists (ASHP) announced an 11medicine list of shortage; which mainly included hospital level antibiotics and anesthetic medications; including meropenem, ceftazidim, ampicillin and doxycycline, as antibiotics and vecuronium, rocuronium, as anesthetics. Also, this list included albuterol and fluticasone which are used to open airways in the lungs [11].

In global levels, the impact on medicine shortage was differed by medicine access level, retail and hospital-only, and type. Use of medicines currently being investigated in trials but not yet fully approved by FDA or so-called investigational treatmentsincluding hydroxychloroquine, lopinavir+ritonavir, tocilizumab and sarilumab - had seen a two-fold increase in use over the past month, with 8 times higher use in hospitals [12]. Medicines used in hospitals for COVID-19-including respiratory treatments, sedatives and pain treatments - had experienced an increase of $100 \%$ to $700 \%$, since the beginning of 
January [12].

In local levels, Iran food and drug administration (IFDA) sale's data indicates that HQ, QC and lopinavir+ritonavir experiences 2, 6 and 23 times increase in their monthly sale volume, respectively; however, IFDA's list of medicine shortage for emergency-supply did not report any shortage of aforementioned medicines and/or the drugs required by pneumonia-related hospitalized COVID-19 patients. One of the explanations for this may be the high stock of raw materials; which is justified by the market uncertainties due to Iran's economic and political factors, which leads companies to over-stock. The other reason was currency allocation to importation of COVID-19 required medications, by the government. For example, lopinavir+ritonavir accounted for $0.18 \%$ (2 of 1101 billion US Dollars) of six-month approved currency order by IFDA to Iran central bank, for raw materials, finished pharmaceuticals and dietary formula.

This COVID-19 related shortage also affected the health market for medical devices and personal protective equipment (PPE), which includes protective goggles and visors, mouth-nose protection equipment, and protective clothing and gloves, that made countries to legislate regulations in this regards. The market entry facilitation and export restrictions of PPE and selected medical devices European Commission (2020/403 of 13 March 2020) is one example, in global levels [13]. In Iran on March 1st 2020, national medical device directorate of Iran announced that restrictions on PPE export is legislated by Iran custom office [14]. Also, in order to expedite the supply of required goods and also to reduce the number of face-to-face visits, the process of issuing emergency licenses for medical equipment supplies has been accelerated by sending them to the online communication system and receiving initial approval within one business day. Customs measures to combat this pandemic included banning the export of masks, medical gown, gloves, disinfectants, soap, detergents and alcohol, and also expediting the issuance of clearance permits for imported items related to coronavirus and exemptions from costume tariffs [15].

- Induced demand and panic buying: Induced demand for stocking medication by public, which is called "panic buying", may cause periodic shortage in the market; especially for chronic disease medications. Studies reported that induced demand in global pharmaceutical market, mainly due to "panic buying" of pharmaceuticals for chronic disorders, was estimated to be $+8.9 \%$, by March 2020 [16]. An study in USA indicated that from 13 th to the 21 st of
March 2020, asthma medications spiked by $65 \%$, and type 2 diabetes medications increased by $25 \%$ [17]. Similarly, medicines treating high cholesterol, migraine, and hypothyroidism also saw a noteworthy increase in claims [17]. Also, in USA, Excess buying for hypertension, Diabetes, respiratory, and mental health and anxiety was $0.6 \%$, $0.3 \%, 0.4 \%, 0.4 \%$ and $0.1 \%$ respectively [12]. In Australia, a one-month-stock regulation for dispensing of prescription medicines, is somehow handling the situation of panic-buying [18]. In Germany, German Federal Institute for Drugs and Medical Devices (BfArM) published an allocation order on the storage and demanddriven supply of human medicines, on March 2020. The allocation order requested the pharmaceutical companies and wholesalers not to supply medicines beyond the usual demand [19]. In contrast, the "stay at home" order in some countries may have caused a decrease in demand; however, in Iran, due to lack of such regulation only induced demand was reported informally by retail pharmacies.

- Supply shortage of both active pharmaceutical ingredients (APIs) and finished products: China and India are the world's main supplies of APIs, key starting materials (KSMs) and also finished pharmaceuticals. As they are struggling with the disease and also a slow-down in production, this may have contributed to shortage and also price increase in essential prescription medicines, including antibiotics. This is more critical when nonsubstitutional essential APIs, such as amoxicillin, potassium clavulanate, ceftriaxone potassium sterile, meropenam, vancomycin, gentamycin and ciprofloxacin are being concerned. In India, the Indian Pharmaceutical Alliance (IPA) asked government to restrict of all pharmaceutical products, APIs and formulation to domestic consumption only. This shortage has already begun to affect API and bulk prices in Indian party trades. The average increase was reported to be about 10-15\%; however, may reach to $50 \%$ in some cases [20].

In global levels, to avoid shortages, FDA and European Commission proposed and published regulations focusing on both demand optimization and rational supply [21]. These regulation revisions include:

- $\quad$ Fast-track approvals for COVID-19-related treatments; In Iran, this is in terms of Iran medicine list (IML) inclusion and registration process.

- Compulsory licensing for potential COVID-19 treatments; however, this is in the context of countries who are World Trade Organization (WTO) members and are following intellectual property laws; and it is not subjected to Iran.

- More regulations to enhance importation, in order to maintain integration of supply chain; however, regarding the economic crisis and currency shortage in Iran and also Iran's NDP component on enhancing local production and 
importation minimization, this regulation is not subjected to current context.

In Iran, again due to over-stocking based on economic and political uncertainties, this impact has not yet to be sensed completely; however, as about $5 \%$ of sale volume and $30 \%$ of sale-value of finished pharmaceuticals [6] and about $50 \%$ of the API are being imported into the country [4], this shortage type will impact the local pharmaceutical industry.

2. Shift of communication and promotions to remote interactions through tele-communication and tele-health: In both global and local levels, due to the social distancing precautions, marketing and promotions of health-care products to providers are being shifted from face-to-face towards remote interactions and tele-communications; for both promotional and patient-support acts. In USA, the number of patients who have visited physician offices or clinics reduced by 70 to $80 \%$ [12].

In Iran insurance coverage for tele-medicine is legislated for the first time by high council of insurance on May 2020. This may lead to long-term behavioral changes in the health market.

\section{Research and development changes}

In global levels, at least 113 medicines or regimens and 53 vaccines are in research and development pipelines or active clinical trials, as therapeutics for patients diagnosed with COVID-19 [12]. As of April 23, 2020, there are about 924 ongoing trials in the world for the treatment of COVID-19. Only $15 \%$ of these studies are based on conventional RCT methods, double-blind and multicenter randomized with comparator arm, but about $40 \%$ are not even randomized [12].

In Iran, HCQ is available through local production with five active suppliers and a price of $0.1 \mathrm{US} \$$ and is being investigated in $64 \mathrm{MOH}-$ registered clinical trials on COVID-19 patients. CQ, which is also available by one local manufacturer with the price of 0.03 US $\$$, is the intervention arm in 29 Iran $\mathrm{MOH}$ trials and lopinavir/ritonavir, which is included in Iran local COVID-19 management guideline for high risk patients as an additive to $\mathrm{CQ}$ or HCQ regimen [22] and is available through generics importation from Indian suppliers with a registered price of 0.82 US\$ per unit, is being investigated in 20 Iran $\mathrm{MOH}$ trials on patients with confirmed COVID-19. In addition, multiple clinical trials are being conducted to test non-IML-included medications; naming favipiravir and remdesevir. Favipiravir is currently being tested through three $\mathrm{MOH}$-supervised clinical trials in Iran and three local manufacturers are conducting pharmacokinetic and stability analysis on aforementioned pharmaceutical strategy. Also, Remdesivir which is an antiviral in first steps of drug development, is being under clinical investigation through Iran MOH-registered clinical trials [23, 24]. This medication was obtained emergency authorization approval by the FDA on May 1st, 2020 for hospitalized patients with severe disease condition [25].

Above being noted, there is a dilemma regarding pseudo-researches and industrial investments on medicines which will be identified as non-effective in the near future; which may eventually pose a considerable burden on the health system. Ethical considerations must be taken into account within the excited decision making about the use of the treatment strategies based on the results of these pseudo-researches [26].

Long-term impacts Approval delays, moving towards selfsufficiency in pharm-production supply chain, industry growth slow-down and possible trend changes in consumption could be seen as long-term impacts of COVID-19 on the health and pharmaceutical market.

1. Delayed approvals for non-COVID-related pharmaceutical products; as all countries, including Iran, are being under pressure of the crisis and their priority is COVID19 management, approval delays may be seen due to several month of application review postponements. In Iran, due to economic crisis, IML inclusion, registrations and reimbursement decisions was being made with a considerable delay; and this situation may maximize it. It also is affected by about one-month semi-closure of regulatory agencies.

2. Moving towards self-sufficiency in pharma industry; potential shortages due to export bans in India and China, who are main suppliers of API and generics, made governments of many countries to consider self-sufficiency in supply chain and they have announced regulations to avoid shortages in such crisis [27]. In this regards, on March 2020 the European commission has published a new guideline concerning foreign direct investment and free movement of capital from third countries; stating that foreign investments, especially those which affect the health market, in European Union (EU), must be subjected to risk-assessments to avoid any harmful impact on the EU's capacity to cover the health needs of its citizens [28].

In Iran, due to sanctions and difficulties in importation, Iran's pharmaceutical industry was going towards selfsufficiency prior to this crisis; however, COVID-19 pandemic may lead to more importation restrictions and further regulation incentives for local manufacturing.

3. Pharmaceutical industry growth slow-down; Coronavirus pandemic resulted in economical slowdowns for many countries and this will possibly lead to pharma industry growth slow-down, which are sensitive to country economic growth; especially, in 
Table 1 The world-wide reported short- and long impact of COVID-19 on pharmaceutical sector

\begin{tabular}{|c|c|c|c|c|c|}
\hline Impact & & & Middle-East [31] & EU5 countries [30] & United States [12] \\
\hline \multirow[t]{11}{*}{ Short-term } & \multirow[t]{8}{*}{$\begin{array}{l}\text { Medication shortage } \\
\text { due to induced } \\
\text { demand }\end{array}$} & \multirow[t]{3}{*}{ COVID-19 related } & $\begin{array}{l}+10.8 \% \text { : OTC category } \\
\quad \text { (cold, cough) }\end{array}$ & $\begin{array}{l}+10.8 \% \text { : OTC } \\
\text { category } \\
\quad \text { (vitamin-- } \\
\text { minerals,...) }\end{array}$ & $\begin{array}{l}\text { Investigational treatments have } \\
\text { seen a } 2 \text {-fold increase }\end{array}$ \\
\hline & & & $+403 \%$ : Personal hygiene & $\begin{array}{l}+62 \% \text { : Personal } \\
\text { hygiene }\end{array}$ & $\begin{array}{l}\text { Medicines used in hospitals for } \\
\text { the treatment of COVID-19 } \\
\text { have increased between } \\
100 \% \text { and } 700 \% \text { since the } \\
\text { beginning of January }\end{array}$ \\
\hline & & & $+67 \%$ : ICU medications & & \\
\hline & & \multirow[t]{3}{*}{ General (panic buying) } & +23\%: Lipid lowering & \multirow[t]{5}{*}{$\begin{array}{l}+7.0 \% \text { : Highest } \\
\text { volume growth in } \\
\text { ATC N class of } \\
\text { RX-category in } \\
\text { Spain }\end{array}$} & $\begin{array}{l}7,6,5,4 \text { and } 2 \text { million excess } \\
\text { prescription in hypertension, } \\
\text { mental health, respiratory, } \\
\text { diabetes and anxiety }\end{array}$ \\
\hline & & & $+40 \%$ : Anti-diabetes & & \\
\hline & & & $\begin{array}{l}+29.1 \%: \\
\quad \text { Anti-hypertensives }\end{array}$ & & \\
\hline & & \multirow[t]{2}{*}{ Supply shortage } & $\begin{array}{l}\text { Medicines for chronic } \\
\text { diseases are at high risk } \\
\text { of shortage or supply } \\
\text { chain }\end{array}$ & & $\begin{array}{l}\text { Supply shortage of both active } \\
\text { APIs and finished products } \\
\text { (About } 40 \% \text { of APIs for the } \\
\text { U.S. generic drug market } \\
\text { come from India) }\end{array}$ \\
\hline & & & & & $\begin{array}{l}\text { Supply shortage of the } \\
\text { COVID- } 19 \text { related complica- } \\
\text { tions treatment }\end{array}$ \\
\hline & \multicolumn{2}{|l|}{ R \& D shifts } & $\begin{array}{l}156 \text { clinical trials are } \\
\text { running for COVID-19 }\end{array}$ & $\begin{array}{l}140 \text { clinical trials are } \\
\text { running for } \\
\text { COVID-19 }\end{array}$ & \\
\hline & \multirow[t]{2}{*}{$\begin{array}{l}\text { Shifts towards } \\
\text { tele-medicine }\end{array}$} & $\begin{array}{l}\text { WhatsApp calls is the most } \\
\text { preferred digital channel } \\
\text { for both patient } \\
\text { consultation and } \\
\text { communication with } \\
\text { peers }\end{array}$ & $\begin{array}{l}320 \% \text { increase (v. PY) in } \\
\text { remote interactions in } \\
\text { Spain. The } \\
\text { corresponding increase } \\
\text { in Italy (v. PY) was } \\
471 \%\end{array}$ & $\begin{array}{l}70-80 \% \text { reduction in } \\
\text { the number of } \\
\text { patient visits to } \\
\text { doctor offices }\end{array}$ & \\
\hline & & $\begin{array}{l}\text { Digital channel has wide } \\
\text { adoption with over } 75 \% \\
\text { of physicians but } \\
\text { physicians prefer } \\
\text { traditional F2F } \\
\text { communication }\end{array}$ & $\begin{array}{l}51 \% \text { decline in specialist } \\
\text { consultations and } 25 \% \\
\text { decline in GPs visits }\end{array}$ & $\begin{array}{l}\text { Tele-medicine } \\
\text { growth accounts } \\
\text { for } 23 \% \text { of } \\
\text { interactions }\end{array}$ & \\
\hline \multirow[t]{3}{*}{ Long-term } & \multirow[t]{2}{*}{$\begin{array}{l}\text { Approval delays } \\
\text { (non-COVID-rela- } \\
\text { ted products) }\end{array}$} & $\begin{array}{l}\text { Clinical trial } 8 \% \text { delay } \\
\text { existing enrolment }\end{array}$ & $\begin{array}{l}\text { Pharma companies report } \\
\text { delay in new trial starts }\end{array}$ & & \\
\hline & & $\begin{array}{l}16 \% \text { delay new trials only } \\
32 \% \text { delay new trials and } \\
\text { existing patient enrolment }\end{array}$ & $\begin{array}{l}\text { Product launches delayed, } \\
\text { disrupted or impacted }\end{array}$ & & \\
\hline & $\begin{array}{l}\text { Shifts towards } \\
\text { self-sufficiency in } \\
\text { pharma industry }\end{array}$ & & $\begin{array}{l}\text { Direct investment and free } \\
\text { movement of capital } \\
\text { from other countries }\end{array}$ & & \\
\hline
\end{tabular}

OTC Over the Counter, ICU Intensive Care Unit, ATC N Anatomical Therapeutic Chemical Classification Nervous system, U.S. United States, v. PY: versus Previous Year, F2F Face-to-Face, GPs General Practitioners, APIs Active Pharmaceutical Ingredients, $R \& D$ Research and Development

countries with pharmerging markets, like Iran. This slowdown in market growth is more due to the entry of newer medications. Because the priorities of pharmaceutical companies change in their portfolio.
However, it should be noted that in previous recessions, there were cases in which the health industry was less sensitive to slowing economic growth and did not always follow this trend [29]. 
4. Ethical considerations: One of the long-term effects of growing clinical research related to the current pandemic is the use of poorly evidence centered therapies. Ethical issues should be considered in the use of these medicines as off-label [26]. In confirming the proposed therapies, the long-term clinical effects of the use of these strategies in the coming years should be examined and healthcare providers should make informed decisions on using off-label therapies in clinical practice.

5. Consumption trend changes in health-related products: Changing habits related to consumption and refilling prescriptions, especially in chronic disease therapeutic areas, might happen; and may also be further affected by the emerging tele-medicine.

Currently, public is concerned with personal hygiene maintenance; using mainly nose/mouth protection, antiinfections material for environment and clothing and hand sanitizers. Due to extended period of pandemic, this consumption may remain in behavioral acts of the public, globally and locally.

The short-term and long-term effects discussed in this paper can be seen in many reported trends around the world [12, 30, 31], and in countries in other regions, such as Africa, these effects will be predictable with increasing the COVID-19 prevalence. The reported impacts shown in Table 1.

\section{Conclusion}

The COVID-19 global pandemic can may be associated with numerous short- and long-term impacts on the health market, mainly the pharmaceutical sector; which can be seen from both global and local perspectives. Identifying these impacts may guide policy-makers in evidence-informed planning and decision-making to combat associated challenges. For proper planning to prevent long-term complications, short-term impacts should be identified and further be measured with appropriate data-analysis. Identification of these effects is essential for policy-maker guidance towards more evidence-informed planning to overcome accompanying challenges; and this may be more important in the context of developing countries with more scares healthcare resources and pharmerging markets.

Acknowledgments Not applicable.

Availability of data and material (data transparency) Not applicable.

Authors' contributions All authors contributed in the design and preparation of the manuscript.

\section{Compliance with ethical standards}

Conflicts of interest/competing interests All the authors declare no conflict of interests which may affect our objectivity.

Code availability Not applicable.

\section{References}

1. Title of subordinate document. In: Coronavirus disease (COVID19) outbreak situation. WHO. 2020. https://www.who.int/ emergencies/diseases/novel-coronavirus-2019. Accessed 23 April 2020.

2. How to Design and Implement a National Drug Policy. Geneva: World Health Organization; 2001.

3. Kebriaeezadeh A, Koopaei NN, Abdollahiasl A, Nikfar S, Mohamadi N. Trend analysis of the pharmaceutical market in Iran; 1997-2010; policy implications for developing countries. DARU J Pharm Sci. 2013;21(1):52.

4. Cheraghali AM. Trends in Iran pharmaceutical market. Iran J Pharm Res: IJPR. 2017;16(1):1-7.

5. Cheraghali AM, Nikfar S, Behmanesh Y, et al. Evaluation of availability, accessibility and prescribing pattern of medicines in the Islamic Republic of Iran. Eastern Mediterr Health $\mathrm{J}=\mathrm{La}$ Revue de Sante de la Mediterranee Orientale = Al-majallah Al-sihhiyah Li-sharq Al-mutawassit. 2004;10(3):406-15.

6. Dinarvand R. New national drug policy in Iran leading to expanded pharmaceutical market and extended access of public to medicines. Iran J Public Health. 2009;38:158-61.

7. Title of subordinate document. In: Iran $\mathrm{MOH}$ guildeline update for COVID-19. Ministry of Health and Medical Education (Iran). http://corona.behdasht.gov.ir. Accessed 28 April 2020.

8. The Lancet Infectious Diseases: Comprehensive COVID-19 hospitalization and death rate estimates help countries best prepare as global pandemic unfolds. Lancet Infect Dis. 30-MAR-2020.

9. Title of subordinate document. In: Drug Shortages Root Causes and Potential Solutions. FDA. https://www.fda.gov/drugs/drugshortages/report-drug-shortages-root-causes-and-potentialsolutions. Updated February 2020.

10. Title of subordinate document. In: Current and Resolved Drug Shortages and Discontinuations Reported to FDA. FDA. https:// www.accessdata.fda.gov/scripts/drugshortages/default.cfm. Accessed February 2020

11. Title of subordinate document. In: ASHP Drug shortage. https:// www.ashp.org/Drug-Shortages/Current-Shortages/DrugShortages-List?page=CurrentShortages. Accessed February 2020.

12. Aitken M, Kleinrock M. Title of subordinate document. In: shifts in healthcare demand, delivery and care during theCOVID-19 era. IQVIA Inc https://www.iqvia.com/insights/the-iqvia-institute/ covid-19/shifts-in-healthcare-demand-delivery-and-care-duringthe-covid-19-era. .

13. COMMISSION RECOMMENDATION (EU) 2020/403: on conformity assessment and market surveillance procedures within the context of the COVID-19 threat: European Commission. https://eur-lex.europa. eu/legal-content/EN/TXT/?qid=1584482018128\&uri=CELEX: 32020H0403. updated 13 March 2020.

14. Title of subordinate document. In: Iran NMDDo. Export ban on personal protective equipment: National Medical Device Directorate of Iran 2020. IFDA. http://imed.ir/. Accessed 1 May 2020.

15. Title of subordinate document. In: Medical equipment entry restrictions. IFDA. http://imed.ir/Default.aspx?PageName=News \&ID= 4556. Accessed 1 May 2020. 
16. Title of subordinate document. In: Panic buying amid coronavirus lockdown helped pharma market grow. https:/www.businessstandard.com/article/companies/panic-buying-amid-coronaviruslockdown-helped-pharma-market-grow-9-120040801570_1.html. Accessed February 2020.

17. Marsh T. Title of subordinate document. In: Live Updates: How Is COVID-19 Affecting Prescription Fills?. https://www.goodrx.com/ blog/medication-fills-rise-during-coronavirus-covid-19-pandemic/.

18. MP THGH. Title of subordinate document. In: ensuring continued access to medicines during the COVID-19 pandemic. TGA. https:// www.health.gov.au/ministers/the-hon-greg-hunt-mp/media/ ensuring-continued-access-to-medicines-during-the-covid-19pandemic. Accessed April 2020.

19. Title of subordinate document. In: German Federal Institute for Drugs and Medical Devices. https://www.bfarm.de/EN/Drugs/ licensing/amInformationen/_node.html. Accessed May 2020.

20. Thacker T. Title of subordinate document. In: Covid-19 impact: government panel lists essential drugs that can run out. The Economic Times https://economictimes.indiatimes.com/industry/ healthcare/biotech/pharmaceuticals/covid-19-impact-governmentpanel-lists-essential-drugs-that-can-run-out/articleshow/74449944. cms?from=mdr. Accessed February 2020.

21. Title of subordinate document. In: Guidelines on the optimal and rational supply of medicines to avoid shortages during the COVID19 outbreak. https://ec.europa.eu/info/sites/info/files/ communication-commission-guidelines-optimal-rational-supplymedicines-avoid.pdf. Accessed April 2020.

22. Title of subordinate document. In: local standard of care- Iranian MOH. Medcare. http://medcare.behdasht.gov.ir/index.aspx?siteid= 312\&fkeyid $=\&$ siteid $=312$ \&pageid $=61966$. Accessed May 2020.

23. Randomzied trial of additional treatments for COVID-19 in hospitalized patients who are all receiving the local standard of careIranian SOLIDARITY multicentre trial [Internet]. Available from: https://www.irct.ir/trial/46930.
24. A single-arm multicenter clinical trial to evaluate the safety and efficacy of Remdesivir in COVID-19 patients with progressive severe acute respiratory syndrome coronavirus 2 (SARS-CoV-2) [Internet]. Available from: https://www.irct.ir/trial/46660.

25. Hinton DM. Remdesivir EUA Letter of Authorization. FDA; 2020.

26. Shojaei A, Salari P. COVID-19 and off label use of drugs: an ethical viewpoint. DARU J Pharm Sci. 2020; https://doi.org/10.1007/ s40199-020-00351-y.

27. Title of subordinate document. In: Covid-19 Impact: Pharma companies feel the pain as prices of key inputs shoot up. The Economic Times. https://economictimes.indiatimes.com/industry/healthcare/ biotech/pharmaceuticals/covid-19-impact-pharma-companies-feelthe-pain-as-prices-of-key-inputs-shoot up/articleshow/74144044. cms?from=mdr. Accessed April 2020.

28. Guidance to the Member States concerning foreign direct investment and free movement of capital from third countries, and the protection of Europe's strategic assets, ahead of the application of Regulation (EU) 2019/452 (FDI Screening Regulation). https:// trade.ec.europa.eu/doclib/docs/2020/march/tradoc_158676.pdf. Accessed March 2020.

29. Dr. Ural. Title of subordinate document. In: Evaluating Pharma Amid COVID-19. https://www.contractpharma.com/contents/ view_online-exclusives/2020-05-18/evaluating-pharma-amidcovid-19/. Accessed 18 May 2020.

30. Title of subordinate document. In: Monitoring the Impact of COVID-19 on the Pharmaceutical Market - EU5. IQVIA. https:// www.iqvia.com/library/white-papers/monitoring-the-impact-ofcovid-19-on-the-pharmaceutical-market-eu5. Accessed 2 June 2020.

31. Title of subordinate document. In: The Impact of COVID-19 on Middle-East Healthcare: Current and Future. IQVIA Webinar. Accessed 21 May 2020.

Publisher's note Springer Nature remains neutral with regard to jurisdictional claims in published maps and institutional affiliations. 